\title{
Use of immunoproteomics to identify immunogenic proteins in a rat model of acute respiratory distress syndrome
}

\author{
ZONGSHU JI $^{1}$, HAIYAN LIU ${ }^{1}$, LINSEN FANG ${ }^{2}$, YOUXIN YU ${ }^{2}$ and ZHENG ZHOU ${ }^{3}$ \\ Departments of ${ }^{1}$ Critical Care Medicine, ${ }^{2}$ Burns and ${ }^{3}$ General Surgery, The First Affiliated \\ Hospital of Anhui Medical University, Hefei, Anhui 230022, P.R. China
}

Received May 31, 2016; Accepted July 17, 2017

DOI: $10.3892 / \mathrm{mmr} .2017 .7557$

\begin{abstract}
Acute respiratory distress syndrome (ARDS) is a common and life-threatening clinical syndrome, and seeking biomarkers of ARDS has been an area of continuing research. The present study hypothesized that alterations to certain immunogenic substances occur in injured lungs and are able to specifically bind with corresponding proteins in the blood, and that these proteins may be readily detected. To investigate this hypothesis, a rat model of ARDS was established by cecal ligation and puncture surgery, and an immunoproteomics approach, using serum as the primary antibody in a western blot analysis, was used with the aim of identifying immunogenic proteins in the injured lungs. Ingenuity Pathway Analysis (IPA) was used for bioinformatics analysis, and mass spectrometric analysis was used to identify a total of 38 differentially expressed immunogenic proteins. Bioinformatics analysis revealed that the top canonical pathways in which the identified proteins may be involved were gluconeogenesis I, glycolysis I, choline degradation I, NADH repair and heme degradation. IPA Biomarker Filter analysis with the terms 'acute respiratory distress syndrome/acute lung injury' was used to screen 13 proteins as candidate biomarkers. These proteins were described as antigens, and suggested that paired antibodies may be detected in the plasma of patients at high risk of ARDS. Analysis of these identified proteins may provide novel insights into the potential pathological mechanisms of ARDS.
\end{abstract}

\section{Introduction}

Acute respiratory distress syndrome (ARDS) is a common and life-threatening clinical syndrome, which accounts for a large number of cases treated in Intensive Care Units; mild ARDS was previously termed acute lung injury (ALI) $(1,2)$. Despite

Correspondence to: Dr Haiyan Liu, Department of Critical Care Medicine, The First Affiliated Hospital of Anhui Medical University, 218 Jixi Road, Hefei, Anhui 230022, P.R. China

E-mail: aquahy@163.com

Key words: acute respiratory distress syndrome, immunoproteomics, biomarkers, Ingenuity Pathway Analysis the use of lung-protective ventilation and comprehensive treatments, the incidence and overall mortality of ARDS has not changed substantially, with the mortality rate remaining at $>40 \%(3,4)$. Early detection and intervention is important to prevent deterioration in patients with ARDS. Therefore, the development of diagnostic tools to identify patients at high risk of ARDS has been the subject of continuing research. Various biomarkers, including receptors for advanced glycation end products (RAGE), surfactant proteins, Clara cell secretory protein (CC16) and certain cytokines, have been demonstrated to be useful in ARDS diagnosis and prognosis (5-8). In addition, proteomics approaches may be able to identify novel ARDS protein biomarkers (9-11). One previous proteomic analysis of lung tissues in animal models has provided novel insight into the mechanisms underlying ALI (12). Using the isobaric tag for relative and absolute quantitation (iTRAQ) approach, a different study identified 132 plasma proteins, among which 16 were differentially expressed in ARDS patients compared with control subjects (10).

An ideal way to study specific diseases is by histopathological examination of tissues from a disease-affected area, which may directly reveal lesions; however, it is difficult to obtain lung specimens from patients with ARDS. Therefore, owing to the convenient accessibility and the ease of repeat sampling, plasma samples have been a focus for biomarker identification. For example, a previous study identified 30 plasma proteins that were altered during the early phase of peritonitis-induced sepsis; the majority of these proteins were revealed to serve important roles in inflammatory responses, whereas other proteins were involved in oxidative and nitrosative stress (13). It is well known that sepsis may lead to multi-organ failure; however, the proteins identified in plasma may not be specific indicators for single-organ damage. Therefore, the present study aimed to determine whether any of the altered plasma proteins were directly associated with the occurrence of subsequent lung injury. It was hypothesized that changes to certain immunogenic substances occurred in injured lungs, and these substances may specifically bind with corresponding proteins in the blood, such that lung injury-associated changes may be detected in the blood.

Immunoproteomics is a technique that involves the separation of proteins by two-dimensional electrophoresis (2-DE) followed by western blotting, and has been used previously to identify immunogenic proteins in various diseases $(14,15)$. 
The present study established a rat model of ARDS, which was induced by cecal ligation and puncture (CLP) surgery, and used an immunoproteomics approach to identify proteins that were altered during lung injury. The ultimate goal was to clinically assess the corresponding proteins identified in the blood plasma that may be associated with lung injury.

\section{Materials and methods}

Establishment of an ARDS model. A total of 12 specificpathogen-free, male Sprague-Dawley rats (weight, 210-250 g) were used in the present study. The rats were obtained from Medical Laboratory Animal Centre of Anhui Medical University (Hefei, China) and housed in an air-conditioned room at a constant temperature $\left(23 \pm 2^{\circ} \mathrm{C}\right)$ under a $12 \mathrm{~h}$ light-dark cycle and with free access to food and water. Animals were fasted for $12 \mathrm{~h}$, but allowed free access to water prior to the experiments. All experimental protocols were approved by The Medical Ethics Committee of the First Affiliated Hospital of Anhui Medical University (Hefei, China).

The CLP technique was conducted according to described previously procedures $(16,17)$. Surgeries were performed following anesthetization of the rats via intraperitoneal injection of $10 \%$ chloral hydrate $(0.3 \mathrm{ml} / 100 \mathrm{~g}$ body weight $)$. The rats were randomly divided into two groups as follows (n=6/group): i) CLP group and ii) Sham-operated control group. CLP was conducted as follows: Under anesthesia, a longitudinal midline incision was made in the skin and the cecum was isolated and ligated below the ileocecal valve, so as not to ligate the ileocecal valve itself, such that intestinal continuity was maintained. Subsequently, the cecum was perforated by two through-and-through punctures using a 20-gauge needle, and the cecum was gently squeezed until a small amount of fecal matter began to exude. The bowel was then repositioned and the abdominal incision was closed. Sham-operated rats underwent laparotomy and the cecum was manipulated without ligation and puncture. Following surgery, sterile saline ( $2 \mathrm{ml} / 100 \mathrm{~g}$ body weight) was administered subcutaneously to all rats in each group. Postoperatively, each rat was placed in a clean cage and allowed free access to food and water. Histopathological changes in the lungs caused by CLP begin within 18-20 h, and high rates of lethality were reported at $\sim 24 \mathrm{~h}(16,17)$. Therefore, the endpoint of the experiment was set at $24 \mathrm{~h}$ post-surgery. At the time of sacrifice, animals were anesthetized and a laparotomy was performed to expose the abdominal aorta, and blood samples (3-4 ml) were collected. Lung tissues were obtained, washed twice with cold saline and immediately stored at $-80^{\circ} \mathrm{C}$ for proteomic analysis, or fixed in $10 \%$ formalin for histopathological assessment. Blood samples were centrifuged at $1,000 \mathrm{x} g$ for $10 \mathrm{~min}$ at $4^{\circ} \mathrm{C}$, and serum was aliquoted and stored at $-80^{\circ} \mathrm{C}$.

Histopathological assessment of lung injury. Histopathological alterations in the lungs were assessed to determine whether the lung injury models had been successfully established. Lung tissues were fixed in $10 \%$ buffered formalin at room temperature for $24 \mathrm{~h}$ and embedded in paraffin. Lung sections $(5 \mu \mathrm{m})$ were stained with hematoxylin and eosin (H\&E) according to standard methods at room temperature, and examined under a light microscope. Lung injury was assessed in a blinded manner, and scored using the method described by Nishina et al (18), which using 5-point scale according to combined assessment of alveolar congestion, hemorrhage, infiltration or aggregation of neutrophils in the airspace or vessel wall, and the thickness of the alveolar wall/hyaline membrane formation: $0=$ minimum damage, $1=$ mild damage, $2=$ moderate damage, $3=$ severe damage, $4=$ maximum damage. The lung injury scores between the two groups were analyzed using the Wilcoxon rank sum test, performed using SPSS version 19.0 (SPSS Inc., Chicago, IL, USA). P<0.05 was considered to indicate a statistically significant difference.

Protein preparation. Lung tissue (200 mg) was homogenized in lysis buffer containing $7 \mathrm{M}$ urea, $2 \mathrm{M}$ thiourea, $4 \%(\mathrm{w} / \mathrm{v})$ 3-[(3-cholamidopropyl) dimethylammonio)-1-propanesulfonate] (CHAPS), $40 \mathrm{mM}$ dithiothreitol (DTT), 1\% Pierce Protease Inhibitor Cocktail (v/v) (Thermo Fisher Scientific, Inc., Waltham, MA, USA), and $2 \%(\mathrm{v} / \mathrm{v})$ Immobiline $\mathrm{pH}$ Gradient (IPG) buffer ( $\mathrm{pH} 3-10)$ on ice. Following vortexing at maximum speed for $30 \mathrm{sec}$, the homogenate was centrifuged at $14,000 \mathrm{x} \mathrm{g}$ at $4^{\circ} \mathrm{C}$ for $20 \mathrm{~min}$. The concentration of proteins in the supernatant was quantified using the Bradford method.

Protein separation by two-dimensional polyacrylamide gel electrophoresis (2-D PAGE). Lung tissue proteins from each group ( $\mathrm{n}=6 /$ group) were pooled and separated by 2-D PAGE as previously described $(14,19)$. A total of $100 \mu \mathrm{g}$ of protein was mixed with rehydration buffer [8 $\mathrm{M}$ urea, $2 \%$ CHAPS, $20 \mathrm{mM}$ DTT, $0.5 \%$ IPG buffer (pH 3-10) and $0.001 \%$ trace bromophenol blue] and applied to IPG strips (pH 3-10; $13 \mathrm{~cm}$; GE Healthcare Life Sciences, Uppsala, Sweden). Isoelectric focusing was performed on an Ettan IPGphor II system (GE Healthcare Life Sciences) at $20^{\circ} \mathrm{C}$, according to the following paradigm: $30 \mathrm{~V}$ for $6 \mathrm{~h}$; $60 \mathrm{~V}$ for $6 \mathrm{~h} ; 500 \mathrm{~V}$ for $1 \mathrm{~h} ; 1,000 \mathrm{~V}$ for $1 \mathrm{~h}$; and $8,000 \mathrm{~V}$ for $3 \mathrm{~h}$. Immediately prior to the second dimension sodium dodecyl sulfate (SDS)-PAGE, the IPG strips were placed in $10 \mathrm{ml}$ equilibration buffer $[50 \mathrm{mM}$ Tris- $\mathrm{HCl}$ ( $\mathrm{pH} 8.8$ ), $6 \mathrm{M}$ urea, 30\% (v/v) glycerol and 2\% SDS] supplemented with $1 \%$ DTT for $15 \mathrm{~min}$ at room temperature, and subsequently incubated in a similar buffer, in which DTT was replaced with $2.5 \%$ iodoacetamide, for $15 \mathrm{~min}$ at room temperature. The equilibrated strips were loaded on top of the vertical slabs of $12.5 \%$ SDS-PAGE gels. 2-D gel electrophoresis was conducted at $5 \mathrm{~W}$ per gel for $30 \mathrm{~min}$ and at $12 \mathrm{~W}$ per gel until the dye front reached the bottom of the gels. 2-D PAGE was repeated three times to minimize variation.

Following SDS-PAGE, some gels were electroblotted onto a polyvinylidene fluoride (PVDF) membrane for western blotting and the remaining gels were visualized by silver staining. The 2-DE images were analyzed by ImageMaster 2D platinum software (Version 5.0, GE Healthcare Bio-Sciences, Pittsburgh, PA, USA).

Identification of immunogenic proteins by western blotting. Proteins separated by SDS-PAGE were transferred to PVDF membranes using Trans-Blot Turbo Transfer System RTA Transfer kit (Bio-Rad Laboratories, Inc., Hercules, CA, USA). Membranes were subsequently blocked with 5\% non-fat dry milk in Tris-buffered saline (TBS) for $2 \mathrm{~h}$. The pooled serum (1:800) from the CLP group or Sham-operated group was used 
A

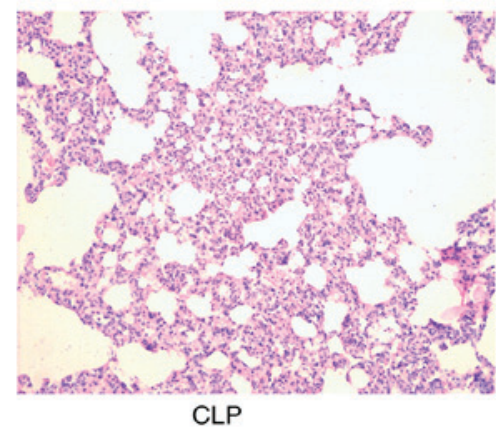

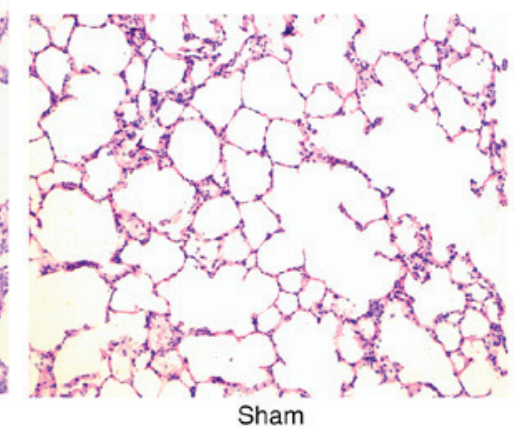

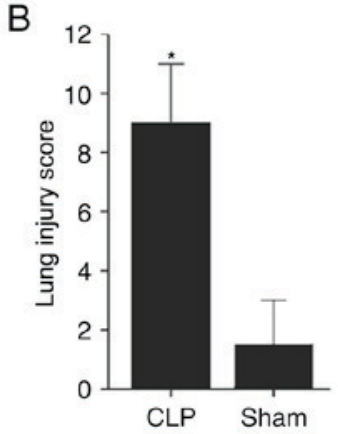

Figure 1. Histopathological evaluation of lung injury. (A) Representative histology of lung tissue stained with hematoxylin and eosin from a CLP-operated rat and a Sham-operated rat. (B) Comparative lung injury scores for the two experimental groups. Magnification, x100. *P<0.05 vs. Sham-operated group. CLP, cecal ligation and puncture.

as the primary antibody, and the membranes were probed for $2 \mathrm{~h}$ at room temperature. Following three washes in TBS containing $0.1 \%$ Tween-20, the membranes were incubated with a horseradish peroxidase-conjugated goat anti-rat IgG H+L (1:1,500; OriGene Technologies, Inc., Beijing, China) for $1 \mathrm{~h}$ at room temperature. Immunogenic protein spots were visualized using ECL Western Blot kit (Beijing CoWin Biotech Co., Ltd., Beijing, China) following three subsequent washing steps. Differential analysis of the expression levels of protein spots was performed using the ImageMaster 2D Platinum software (Version 5.0, GE Healthcare Bio-Sciences).

In-gel enzyme digestion and matrix-assisted laser desorption/ionization time-of-flight/time-of-flight (MALDITOF/TOF) mass spectrometry. Gel excision and derivatization steps were all performed at room temperature, unless otherwise stated. The differentially expressed immunogenic protein spots from silver stained gels were excised and washed twice with double-distilled $\mathrm{H}_{2} \mathrm{O}$, placed in fresh solutions containing $30 \mathrm{mM} \mathrm{K}_{3} \mathrm{Fe}(\mathrm{CN})_{6} / 100 \mathrm{mM} \mathrm{Na}_{2} \mathrm{~S}_{2} \mathrm{O}_{3}$ (1:1) for $2 \mathrm{~min}$ until destained, and washed again to halt the reaction. The gel pieces were dehydrated with acetonitrile (ACN) for $5 \mathrm{~min}$, the ACN was washed off and the samples were air-dried. Subsequently, the gels were incubated in $10 \mathrm{mM}$ DTT at $56^{\circ} \mathrm{C}$ for $1 \mathrm{~h}$, followed by incubation in $55 \mathrm{mM}$ iodoacetamide (IAA) in the darkroom for $45 \mathrm{~min}$. IAA was aspirated off and the gel spots were dehydrated with $25 \mathrm{mM} \mathrm{NH} \mathrm{HCO}_{3}$, followed by $50 \%$ ACN and finally $100 \%$ ACN, and air-dried. Dried gel pieces were rehydrated with trypsin (Promega Corporation, Madison, WI, USA) in $25 \mathrm{mM} \mathrm{NH}_{4} \mathrm{HCO}_{3}$ at $4^{\circ} \mathrm{C}$ for $30 \mathrm{~min}$. The excess liquid was discarded and the samples were incubated at $37^{\circ} \mathrm{C}$ overnight (10-14 h). A $0.1 \%$ concentration of trifluoroacetic acid (TFA) was added to stop the reaction. Samples were spotted onto a $600 \mu \mathrm{m}$ AnchorChip MALDI probe (Bruker Daltonics GmbH, Bremen, Germany) for mass spectrometry on a TOF Ultraflex II MALDI-TOF/TOF mass spectrometer (Bruker Daltonics GmbH). The Bruker Peptide Calibration Mixture was used for external calibration. The resulting peptide mass lists were searched in the NCBI-non-redundant sequence database (NCBI-nr 20150516: 66,926,000 sequences; 23,973,512,723 residues) using the MASCOT search engine (http://202.195.183.2/mascot/) with the following parameters: Trypsin as enzyme, cysteine carbamidomethylation, methionine oxidation, minimum mass accuracy 100 parts/million and 1 missed cleavage site allowed. MASCOT protein scores $>62$ were considered statistically significant $(\mathrm{P}<0.05)$.

Bioinformatics analysis. To further explore the differentially expressed immunogenic proteins, Ingenuity Pathway Analysis (IPA; www.ingenuity.com) was performed to characterize the biological functions and pathways of these proteins. Associated networks were built among the differentially expressed immunogenic proteins and the IPA database proteins. The top canonical pathways were presented with P-values calculated using a right-tailed Fisher's exact test. IPA Biomarker Filter analysis was used to optimize the candidate biomarkers from the differentially expressed immunogenic proteins; 'acute respiratory distress syndrome' and 'acute lung injury' were used as filtered terms.

\section{Results}

Histopathological evaluation of lung injury. H\&E staining was performed to observe histopathological alterations in the lung tissues of each group at $24 \mathrm{~h}$ post-surgery. Examination of the tissues revealed vascular congestion, interstitial edema, inflammatory cell infiltration and pulmonary hemorrhage in the CLP group, whereas the lung tissues from the Sham group exhibited minimal changes with scattered interstitial infiltrates (Fig. 1A). The mean lung injury score of the CLP rats was 8.83 (range, 6-11), which was significantly higher compared with that of the Sham group (mean, 1.33; range, 0-3; $\mathrm{P}<0.05$; Fig. 1B). The histopathological results indicated that the lung injury model was successfully established and was suitable for the detection of protein expression differences following CLP.

2-DE profiles and western blotting analysis. To identify immunogenic proteins in the lung tissues, protein extracts were separated by 2 -DE followed by western blotting. Silver stained gels were scanned; image analysis identified a total of 1,909 protein spots detected in both groups, with molecular masses ranging from $10-100 \mathrm{kDa}$ in the $3-10 \mathrm{pI}$ range. The proteins were transferred to a PVDF membrane and western blotting was performed using pooled serum samples from the CLP or Sham rats as the primary antibody. Positive spots recognized by sera on the membranes were aligned and matched with the blots on silver stained gels. A total of 27 immunogenic protein spots were identified in the CLP group, and 60 immunogenic 
A

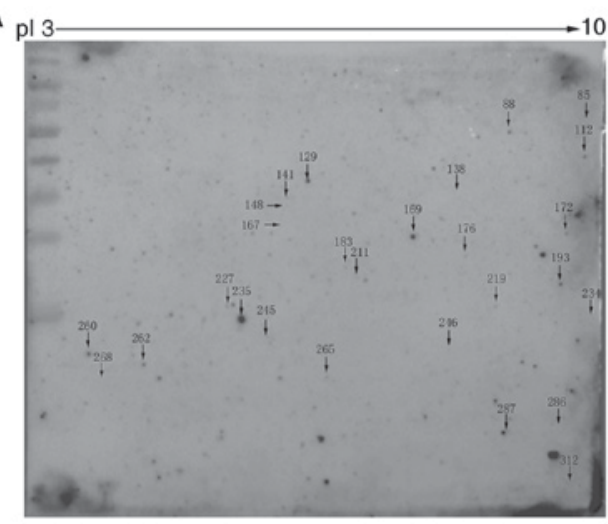

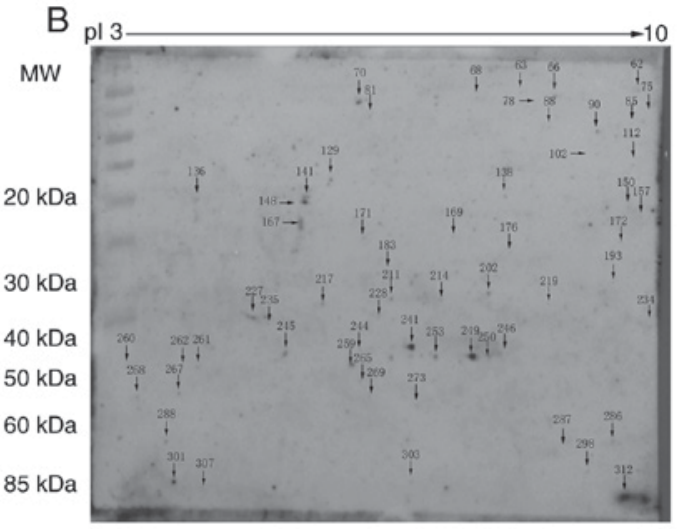

Figure 2. Silver stained 2-dimensional electrophoresis protein maps of lung tissues. Lung tissue protein extracts were separated by two-dimensional PAGE from (A) the CLP-operated group and (B) the Sham-operated group. Spots marked with a number were immunogenic proteins identified by western blotting. CLP, cecal ligation and puncture; pI, isoelectric point; $\mathrm{MW}$, molecular weight.

protein spots were identified in the Sham group (Fig. 2A and $\mathrm{B}$, respectively).

Identification of the ARDS-associated immunogenic proteins. The immunogenic protein spots that exhibited a $>2$-fold difference in intensity between the CLP-operated group and the Sham-operated group were manually excised and used for mass spectrometry. In total, 38 proteins were successfully identified from these spots. Among them, 14 proteins were highly expressed in the CLP group, whereas 24 proteins were highly expressed in the Sham group. Details of the experimental findings for these proteins are shown in Table I. According to the bioinformatics annotations, 10 proteins $(26.32 \%)$ were enzymes, 6 proteins (15.78\%) were kinases and transcription regulators $(7.89 \%$ respectively), and 4 proteins $(10.52 \%)$ were phosphatases, ion channels, transmembrane receptors, and transporters (2.63\% respectively). A total of 18 proteins $(47.37 \%)$ were not classified to any families, including sperm flagellar 2 (SPEF2; also known as KPL2) and selenium-binding protein 1 (SELENBP1; also known as SBP1).

Functional characteristics of the differentially expressed immunogenic proteins. A total of 38 differentially expressed immunogenic proteins were analyzed by IPA to determine their putative molecular networks, molecular and cellular functions, and canonical pathways. With regard to the category of diseases and biofunctions, the top five significant diseases and disorders associated with the differentially expressed immunogenic proteins in the present study were as follows: i) Hematological disease; ii) immunological disease; iii) inflammatory disease; iv) inflammatory response and v) and respiratory disease. Enolase 1 (ENO1), glyceraldehyde-3-phosphate dehydrogenase (GAPDH) and SELENBP1 were involved in these categories. The top five canonical pathways included gluconeogenesis I, glycolysis I, choline degradation I, NADH repair and heme degradation (Fig. 3). In addition, phosphoglycerate kinase 1 (PGK1), ENO1, GAPDH and malate dehydrogenase $2(\mathrm{MDH} 2)$ participate in gluconeogenesis or glycolysis pathways. Finally, using IPA Biomarker Filter analysis with the terms 'acute respiratory distress syndrome/acute lung injury', 13 proteins were identified as candidate biomarkers (Fig. 4).

\section{Discussion}

To identify ARDS biomarkers, an immunoproteomics approach was used to detect immunogenic proteins in an animal model of ARDS. Through mass spectrometric analysis, 38 differentially expressed immunogenic proteins were successfully identified. Bioinformatics analysis demonstrated that the most significant diseases and disorders in which the identified proteins were associated with were immunological disease, inflammatory disease, inflammatory responses and respiratory disease. Using IPA Biomarker Filter analysis, 13 differentially expressed proteins in the present study were identified as candidate biomarkers of ARDS.

Inflammatory cytokines, such as tumor necrosis factor $\alpha$ (TNF- $\alpha$ ), interleukin (IL)-1 $\beta$ and IL-6, and molecules derived from injured lung tissues, such as surfactant proteins, RAGE, CC-16, have been previously reported as candidate biomarkers of ARDS $(20,21)$. However, these factors were not identified in the present study. The differentially expressed proteins identified in this study were described as antigenic, and among the evaluated proteins, ENO1 and enhancer of polycomb homolog 1 (EPC1) have been previously described as antigenic $(22,23)$. ENO1 is a multifunctional enzyme that has functions in various processes, in addition to its role in glycolysis (24). Increased levels of ENO1 autoantibody have been observed in the serum of patients with rheumatoid arthritis and cholangiocarcinoma $(22,25)$. A previous proteomics study identified sputum ENO1 as a potential biomarker to aid in the diagnosis of early-stage lung cancer (26). Increased ENO1 and protein disulfide isomerase-associated 3 were also observed in alveolar epithelial injury and remodeling, which is strongly associated with chronic lung diseases (27). EPC1 is a chromatin protein that modulates skeletal muscle differentiation and induces vascular smooth muscle cell (VSMC) differentiation. EPC1 expression was demonstrated to be upregulated during VSMC differentiation and decreased by platelet-derived growth factor BB treatment $(28,29)$. Recently, EPC1 was characterized and isolated from Echinococcus granulosus protoscoleces as a highly antigenic protein useful in the diagnosis of cystic echinococcosis (23). Although the roles of ENO1 and EPC1 in ARDS require further investigation, the isolation and identification of these 
Table I. Differentially expressed immunogenic proteins in lung tissues from CLP-operated rats compared with Sham-operated rats.

\begin{tabular}{|c|c|c|c|c|c|c|}
\hline $\begin{array}{l}\text { Spot } \\
\text { ID }\end{array}$ & $\begin{array}{l}\text { Accession } \\
\text { number }\end{array}$ & Score & $\mathrm{Mr}$ & $\begin{array}{l}\text { Fold } \\
\text { change }^{\mathrm{a}}\end{array}$ & $\begin{array}{l}\text { Protein } \\
\text { symbol }\end{array}$ & Protein name \\
\hline 66 & gil6978511 & 168 & 12831 & $-1,000$ & SPEG & Striated muscle-specific serine \\
\hline 75 & gil564388675 & 218 & 39366 & $-1,000$ & SLC25A42 & $\begin{array}{l}\text { Mitochondrial coenzyme A transporter } \\
\text { SLC25A42 isoform X2 }\end{array}$ \\
\hline 85 & gil149062136 & 77 & 14970 & 3.419 & RGD1560544 & $\begin{array}{l}\text { Similar to chromosome } 11 \text { open reading } \\
\text { frame } 2 \text { (predicted), isoform CRA_b }\end{array}$ \\
\hline 88 & gil149068094 & 205 & 26511 & 3.431 & LOC81691 & $\begin{array}{l}\text { Similar to exonuclease NEF-sp } \\
\text { (predicted), isoform CRA_f }\end{array}$ \\
\hline 112 & gil149034857 & 306 & 16896 & 30.4 & RASL11A & RAS-like family 11 member A, isoform CRA_b \\
\hline 129 & gil238859563 & 129 & 19694 & 2.651 & DCTD & Deoxycytidylate deaminase isoform 2 \\
\hline 136 & gil149026453 & 220 & 19686 & $-1,000$ & CDH18 & Cadherin 18 , type 2 (predicted) \\
\hline 138 & gil149035234 & 263 & 21183 & -2.346 & FIP1L1 & FIP1-like 1 (S. cerevisiae), isoform CRA_a \\
\hline 141 & gil149056821 & 95 & 20992 & -3.557 & PGLYRP1 & $\begin{array}{l}\text { Peptidoglycan recognition protein } 1 \text {, } \\
\text { isoform CRA_a }\end{array}$ \\
\hline 148 & gil149039413 & 216 & 22555 & -12.347 & C9ORF173 & $\begin{array}{l}\text { Similar to hypothetical gene supported by } \\
\text { AK097565; BC033939, isoform CRA_b }\end{array}$ \\
\hline 157 & gil157819619 & 199 & 22194 & $-1,000$ & BLVRB & Flavin reductase (NADPH) \\
\hline 167 & gil157817749 & 72 & 22879 & -5.265 & EXOSC3 & Exosome complex component RRP40 \\
\hline 169 & gil672082453 & 227 & 24158 & 11.429 & NUDT5 & Predicted: ADP-sugar pyrophosphatase isoform X1 \\
\hline 172 & gil20750357 & 255 & 23927 & 5.31 & PLBD2 & Putative phospholipase B-like 2 \\
\hline 176 & gil71043720 & 140 & 26432 & 2.074 & YIPF6 & Protein YIPF6 \\
\hline 183 & gil189011608 & 256 & 26522 & -2.742 & YEATS4 & YEATS domain-containing protein 4 \\
\hline 193 & gil149057763 & 107 & 27597 & 4.37 & VDAC3 & $\begin{array}{l}\text { Voltage-dependent anion channel 3, } \\
\text { isoform CRA_b }\end{array}$ \\
\hline 211 & gil7739682 & 233 & 28227 & -2.044 & A1BG & Liver regeneration-related protein 1 \\
\hline 217 & gil157818187 & 174 & 31373 & $-1,000$ & TFAP2D & Transcription factor AP-2- $\delta$ \\
\hline 219 & gil77404265 & 174 & 33493 & 3.31 & JAM2 & Junctional adhesion molecule B precursor \\
\hline 227 & gil8393418 & 75 & 36090 & -2.492 & GAPDH & Glyceraldehyde-3-phosphate dehydrogenase \\
\hline 228 & gil42476181 & 140 & 36117 & $-1,000$ & $\mathrm{MDH} 2$ & Malate dehydrogenase, mitochondrial precursor \\
\hline 234 & gil158138555 & 220 & 37513 & -2.33 & $\mathrm{AKR} 1 \mathrm{Cl}$ & Aldo-keto reductase family 1 , member $\mathrm{C}$-like \\
\hline 235 & gil672029914 & 66 & 38232 & 24.228 & LOC689092 & $\begin{array}{l}\text { Predicted: } \mathrm{N} \text {-acetyllactosaminide } \beta-1,6-\mathrm{N} \text { - } \\
\text { acetylglucosaminyl-transferase, isoform A-like }\end{array}$ \\
\hline 241 & gil274324174 & 220 & 40344 & $-1,000$ & WARS2 & Tryptophan-tRNA ligase, mitochondrial \\
\hline 245 & gil19705521 & 213 & 14094 & -5.703 & Mk1 & Mk1 protein \\
\hline 246 & gil293342999 & 174 & 42109 & -6.374 & POTEF & Predicted: POTE ankyrin domain family member F \\
\hline 250 & gil149035278 & 160 & 42158 & -1000 & TEC & TEC protein tyrosine kinase, isoform CRA_a \\
\hline 259 & gil40254752 & 210 & 44909 & -1000 & PGK1 & Phosphoglycerate kinase 1 \\
\hline 260 & gil60422786 & 134 & 47737 & 7.299 & NEMF & Nuclear export mediator factor \\
\hline 262 & gil38649320 & 75 & 51736 & 9.404 & ENO1 & Eno1 protein \\
\hline 265 & gil18266692 & 112 & 53069 & 2.926 & SELENBP1 & Selenium-binding protein 1 \\
\hline 268 & gil59808405 & 212 & 52825 & -2.224 & GATAD2A & GATA zinc-finger domain-containing protein $2 \mathrm{~A}$ \\
\hline 286 & gil58219535 & 125 & 55691 & -3.652 & PIGV & GPI mannosyltransferase 2 \\
\hline 287 & gil66910999 & 175 & 61481 & 3.13 & SPEF2 & Sperm flagellar protein 2 \\
\hline 301 & gil38454200 & 182 & 67088 & -1000 & $\mathrm{CHDH}$ & Choline dehydrogenase, mitochondrial \\
\hline 303 & gil149034390 & 238 & 68243 & -1000 & Ankrd24 & $\begin{array}{l}\text { Ankyrin repeat domain } 24 \text { (predicted), } \\
\text { isoform CRA_a }\end{array}$ \\
\hline 312 & gil293342784 & 161 & 85084 & -70.637 & EPC1 & $\begin{array}{l}\text { Predicted: Enhancer of polycomb homolog } 1 \\
\text { isoform X2 }\end{array}$ \\
\hline
\end{tabular}

${ }^{a}$ Fold change $=\mathrm{CLP} /$ sham; Fold change $>0$ indicates higher expression in the CLP group, whereas fold change $<0$ indicates higher expression in the Sham group. Mr, nominal mass; CLP, cecal ligation and puncture. 


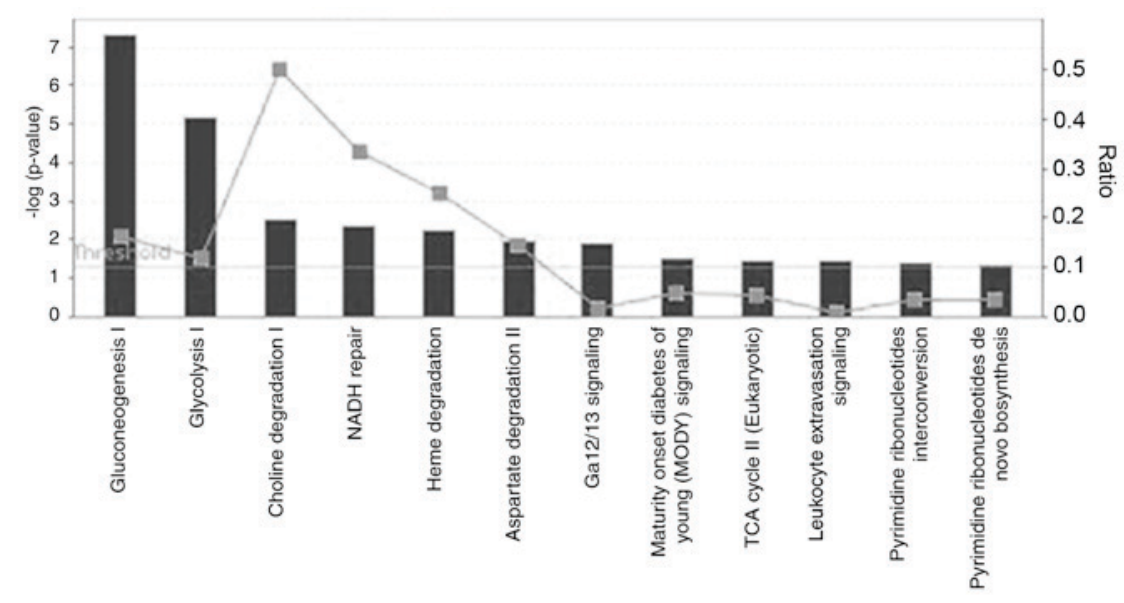

Figure 3. Top canonical pathways in which the differentially expressed immunogenic proteins were predicted to participate. Pathway enrichment (squares) and significance value is presented. TCA, tricarboxylic acid.

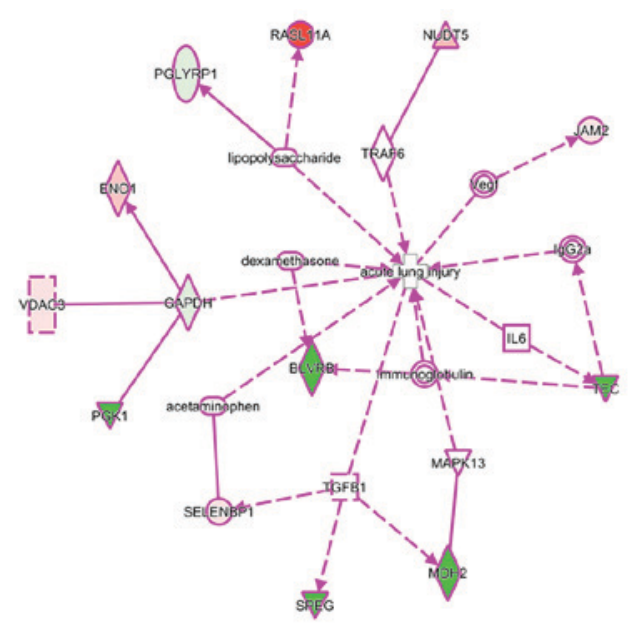

Figure 4. Candidate biomarkers for acute respiratory distress syndrome that were screened from the differentially expressed immunogenic proteins. Upregulated proteins (red) and downregulated proteins (green) in the cecal ligation and puncture-operated group are presented. Dashed arrows indicate indirect actions and solid arrows indicate direct actions of proteins.

antigenic proteins suggested that they may be feasible for use in immunoproteomics.

The roles of the majority of the identified immunogenic proteins in ARDS remain unclear. IPA analysis revealed that PGK1, ENO1, GAPDH and MDH2 participated in canonical glycolysis or gluconeogenesis pathways. However, these proteins exhibited inconsistent regulatory changes in the present study, which suggested that disordered carbohydrate metabolism may be involved the pathogenesis of ARDS. A previous study reported that during ALI, stretching of the pulmonary epithelial cells may result in the inhibition of succinate dehydrogenase expression, in association with the normoxic stabilization of hypoxia-inducible factor (HIF)-1A. Alveolar epithelial HIF1A expression was reported to enhance the glycolytic carbohydrate flux and optimize mitochondrial respiration (30). HIF-dependent prevention of mitochondrial dysfunction increases alveolar epithelial ATP production and prevents the accumulation of reactive oxygen species and lung inflammation (30).
A previous study reported that acrolein-induced ALI is accompanied by a varied metabolomic pattern of energetic stress (31). Four metabolites that differed from the controls were identified in the plasma of sepsis-induced ALI patients; computational data analysis to identify the metabolic networks also provided information regarding the enzymes involved in ALI and the genes that encoded them (32). In addition to the changes in carbohydrate metabolic enzymes aforementioned, the present study identified other proteins involved in choline degradation, aspartate degradation, pyrimidine ribonucleotide interconversion and de novo biosynthesis that were also downregulated in rats with ALI. Furthermore, molecular network analysis revealed that the differentially expressed proteins were associated with one another, directly or indirectly. Consistent with these previous studies, data from the present study suggested that metabolic dysregulation may be associated with the development of ARDS.

Diffuse alveolar damage is a morphological hallmark of ARDS; however, bronchiolar cells may also be seriously damaged in ARDS $(33,34)$. Autopsy studies of the lung tissue of subjects that succumbed to ARDS have revealed epithelial denudation, inflammation and airway wall thickening with extracellular matrix remodeling in distal airways (34). CC16 secreted by the Clara cells of the distal respiratory epithelium is considered to be a marker of lung injury (35). Therefore, another protein identified in the present study, SPEF2, was of interest. SPEF2 is predominantly expressed in ciliated tissues, including lung, trachea, testis and brain tissue (36-38). It is required for ciliary motility and spermatogenesis, and the loss of SPEF2 function was reported to result in severe spermatogenic defects (36). SPEF2 was also reported to have an important role in the differentiation and function of ciliated cells in the airway (37). In the present study, the differential expression of SPEF2 indicated that ciliated cells were injured, and SPEF2 may also be a potential marker of lung injury.

Another protein identified in the present study, SELENBP1, was not classified into any of the functional families. SELENBP1 is a member of the selenoprotein family and is expressed in a variety of tissue types, including the lungs. It has been previously suggested that this protein mediates the intracellular transport of selenium $(39,40)$. Low SELENBP1 
expression has been reported in several tumor types, and was suggested to be a potential biomarker for cancer progression and prognosis $(41,42)$. Recently, SELENBP1 was identified as a negative regulator of HIF1A (42); inhibition of HIF1A has a protective role in lung injury induced by trauma and hemorrhagic shock, which may be associated with the regulation of the inducible nitric oxide synthase/nitric oxide pathway by HIF1A in lung tissue (43). In the present study, SELENBP1 was revealed to be upregulated in the ARDS model compared with the control. The relationships between SELENBP1, HIF1A and ARDS require further investigation.

Certain limitations to the design of the present study must be noted. By comparing the histopathological changes in lung injury with the controls $24 \mathrm{~h}$ post-induction, a research time point was selected for analysis and, thus, the immunoproteomic study at that point did not reflect early ARDS, and no study was conducted on sequential proteomic changes according to the course of ARDS. Therefore, future studies must investigate the immunogenic proteins identified in this experiment with regard to the early detection of ARDS in sepsis patients.

In summary, 38 differentially expressed proteins were identified in the rat model of ARDS using an immunoproteomic method. These proteins were described as antigens, and paired antibodies are predicted to be detected in the plasma of patients at high risk of ARDS. Analysis of these identified proteins may provide novel insights into the potential pathological mechanisms of ARDS.

\section{Acknowledgements}

The authors would like to thank Mr. Fuqiang Wang (Analysis Center of Nanjing Medical University, Nanjing, China) for his assistance in the proteomics techniques and mass spectrometric analysis.

\section{References}

1. Bernard GR, Artigas A, Brigham KL, Carlet J, Falke K, Hudson L, Lamy M, LeGall JR, Morris A and Spragg R: Report of the American-European Consensus conference on ARDS: Definitions, mechanisms, relevant outcomes and clinical trial coordination. The Consensus Committee. Intensive Care Med 20: 225-232, 1994

2. ARDS Definition Task Force; Ranieri VM, Rubenfeld GD, Thompson BT, Ferguson ND, Caldwell E, Fan E, Camporota L and Slutsky AS: Acute respiratory distress syndrome: The Berlin Definition. JAMA 307: 2526-2533, 2012.

3. Villar J, Blanco J, Añón JM, Santos-Bouza A, Blanch L, Ambrós A, Gandía F, Carriedo D, Mosteiro F, Basaldúa S, et al: The ALIEN study: Incidence and outcome of acute respiratory distress syndrome in the era of lung protective ventilation. Intensive Care Med 37: 1932-1941, 2011.

4. Villar J, Sulemanji D and Kacmarek RM: The acute respiratory distress syndrome: Incidence and mortality, has it changed? Curr Opin Crit Care 20: 3-9, 2014.

5. Determann RM, Millo JL, Waddy S, Lutter R, Garrard CS and Schultz MJ: Plasma CC16 levels are associated with development of ALI/ARDS in patients with ventilator-associated pneumonia: A retrospective observational study. BMC Pulm Med 9: 49, 2009

6. Nakamura T, Sato E, Fujiwara N, Kawagoe Y, Maeda S and Yamagishi S: Increased levels of soluble receptor for advanced glycation end products (sRAGE) and high mobility group box 1 (HMGB1) are associated with death in patients with acute respiratory distress syndrome. Clin Biochem 44: 601-604, 2011.

7. McClintock D, Zhuo H, Wickersham N, Matthay MA and Ware LB: Biomarkers of inflammation, coagulation and fibrinolysis predict mortality in acute lung injury. Crit Care 12: R41, 2008 .
8. Cheng IW, Ware LB, Greene KE, Nuckton TJ, Eisner MD and Matthay MA: Prognostic value of surfactant proteins A and D in patients with acute lung injury. Crit Care Med 31: 20-27, 2003.

9. Bowler RP, Duda B, Chan ED, Enghild JJ, Ware LB, Matthay MA and Duncan MW: Proteomic analysis of pulmonary edema fluid and plasma in patients with acute lung injury. Am J Physiol Lung Cell Mol Physiol 286: L1095-L1104, 2004.

10. Chen X, Shan Q, Jiang L, Zhu B and Xi X: Quantitative proteomic analysis by iTRAQ for identification of candidate biomarkers in plasma from acute respiratory distress syndrome patients. Biochem Biophys Res Commun 441: 1-6, 2013.

11. Bhargava M, Becker TL, Viken KJ, Jagtap PD, Dey S, Steinbach MS, Wu B, Kumar V, Bitterman PB, Ingbar DH and Wendt $\mathrm{CH}$ : Proteomic profiles in acute respiratory distress syndrome differentiates survivors from non-survivors. PLoS One 9: e109713, 2014.

12. Liu D, Mao P, Huang Y, Liu Y, Liu X, Pang X and Li Y: Proteomic analysis of lung tissue in a rat acute lung injury model: Identification of PRDX1 as a promoter of inflammation. Mediators Inflamm 2014: 469358, 2014.

13. Thongboonkerd V, Chiangjong W, Mares J, Moravec J, Tuma Z, Karvunidis T, Sinchaikul S, Chen ST, Opatrný K and Matejovic M: Altered plasma proteome during an early phase of peritonitis-induced sepsis. Clin Sci (Lond) 116: 721-730, 2009.

14. Zhou Z, Liu H, Gu G, Wang G, Wu W, Zhang C and Ren J: Immunoproteomic to identify antigens in the intestinal mucosa of Crohn's disease patients. PLoS One 8: e81662, 2013.

15. Bunk S, Susnea I, Rupp J, Summersgill JT, Maass M, Stegmann W, Schrattenholz A, Wendel A, Przybylski M and Hermann C: Immunoproteomic identification and serological responses to novel chlamydia pneumoniae antigens that are associated with persistent C. pneumoniae infections. J Immunol 180: 5490-5498, 2008.

16. Rittirsch D, Huber-Lang MS, Flierl MA and Ward PA: Immunodesign of experimental sepsis by cecal ligation and puncture. Nat Protoc 4: 31-36, 2009.

17. Brooks HF, Osabutey CK, Moss RF, Andrews PL and Davies DC: Caecal ligation and puncture in the rat mimics the pathophysiological changes in human sepsis and causes multi-organ dysfunction. Metab Brain Dis 22: 353-373, 2007.

18. Nishina K, Mikawa K, Takao Y, Maekawa N, Shiga M and Obara H: ONO-5046, an elastase inhibitor, attenuates endotoxin-induced acute lung injury in rabbits. Anesth Analg 84: 1097-1103, 1997.

19. Wu J, Wang F, Gong Y,Li D, Sha J, Huang X and Han X: Proteomic analysis of changes induced by nonylphenol in Sprague-Dawley rat Sertoli cells. Chem Res Toxicol 22: 668-675, 2009.

20. Terpstra ML, Aman J, van Nieuw Amerongen GP and Groeneveld AB: Plasma biomarkers for acute respiratory distress syndrome: A systematic review and meta-analysis*. Crit Care Med 42: 691-700, 2014.

21. Fujishima S: Pathophysiology and biomarkers of acute respiratory distress syndrome. J Intensive Care 2: 32, 2014.

22. Rucksaken R, Pairojkul C, Pinlaor P, Khuntikeo N, Roytrakul S, Selmi C and Pinlaor S: Plasma autoantibodies against heat shock protein 70, enolase 1 and ribonuclease/angiogenin inhibitor 1 as potential biomarkers for cholangiocarcinoma. PLoS One 9: e103259, 2014.

23. Etebar F, Jalousian F, Hosseini SH, Kordafshari S and Najafi A: Immunoproteomics approach for EPC1 antigenic epitope prediction of G1 and G6 strains of Echinococcus granulosus. Parasitol Res 112: 3129-3135, 2013

24. Capello M, Ferri-Borgogno S, Cappello P and Novelli F: $\alpha$-Enolase: A promising therapeutic and diagnostic tumor target. FEBS J 278: 1064-1074, 2011.

25. Lee JY, Choi IA, Kim JH, Kim KH, Lee EY, Lee EB, Lee YM and Song YW: Association between anti-Porphyromonas gingivalis or anti- $\alpha$-enolase antibody and severity of periodontitis or rheumatoid arthritis (RA) disease activity in RA. BMC Musculoskelet Disord 16: 190, 2015.

26. Yu L, Shen J, Mannoor K, Guarnera M and Jiang F: Identification of ENO1 as a potential sputum biomarker for early-stage lung cancer by shotgun proteomics. Clin Lung Cancer 15: 372-378. e1, 2014.

27. Mutze K, Vierkotten S, Milosevic J, Eickelberg O and Königshoff M: Enolase 1 (ENO1) and protein disulfide-isomerase associated 3 (PDIA 3 ) regulate Wnt $/ \beta$-catenin-driven trans-differentiation of murine alveolar epithelial cells. Dis Model Mech 8: 877-890, 2015. 
28. Kee HJ, Kim JR, Nam KI, Park HY, Shin S, Kim JC, Shimono Y, Takahashi M, Jeong MH, Kim N, et al: Enhancer of polycomb1, a novel homeodomain only protein-binding partner, induces skeletal muscle differentiation. J Biol Chem 282: 7700-7709, 2007.

29. Joung H, Kwon JS, Kim JR, Shin S, Kang W, Ahn Y, Kook H and Kee HJ: Enhancer of polycomb1 lessens neointima formation by potentiation of myocardin-induced smooth muscle differentiation. Atherosclerosis 222: 84-91, 2012.

30. Eckle T, Brodsky K, Bonney M, Packard T, Han J, Borchers CH Mariani TJ, Kominsky DJ, Mittelbronn M and Eltzschig HK HIF1A reduces acute lung injury by optimizing carbohydrate metabolism in the alveolar epithelium. PLoS Biol 11: e1001665, 2013.

31. Fabisiak JP, Medvedovic M, Alexander DC, McDunn JE, Concel VJ, Bein K, Jang AS, Berndt A, Vuga LJ, Brant KA, et al: Integrative metabolome and transcriptome profiling reveals discordant energetic stress between mouse strains with differential sensitivity to acrolein-induced acute lung injury. Mol Nutr Food Res 55: 1423-1434, 2011.

32. Stringer KA, Serkova NJ, Karnovsky A, Guire K, Paine R III and Standiford TJ: Metabolic consequences of sepsis-induced acute lung injury revealed by plasma ${ }^{1} \mathrm{H}$-nuclear magnetic resonance quantitative metabolomics and computational analysis. Am J Physiol Lung Cell Mol Physiol 300: L4-L11, 2011.

33. Sarmiento X, Guardiola JJ, Almirall J, Mesalles E, Mate JL, Soler M and Klamburg J: Discrepancy between clinical criteria for diagnosing acute respiratory distress syndrome secondary to community acquired pneumonia with autopsy findings of diffuse alveolar damage. Respir Med 105: 1170-1175, 2011.

34. Morales MM, Pires-Neto RC, Inforsato N, Lanças $T$, da Silva LF, Saldiva PH, Mauad T, Carvalho CR, Amato MB and Dolhnikoff M: Small airway remodeling in acute respiratory distress syndrome: A study in autopsy lung tissue. Crit Care 15: R4, 2011.
35. Kropski JA, Fremont RD, Calfee CS and Ware LB: Clara cell protein (CC16), a marker of lung epithelial injury, is decreased in plasma and pulmonary edema fluid from patients with acute lung injury. Chest 135: 1440-1447, 2009.

36. Sironen A, Kotaja N, Mulhern H, Wyatt TA, Sisson JH, Pavlik JA, Miiluniemi M, Fleming MD and Lee L: Loss of SPEF2 function in mice results in spermatogenesis defects and primary ciliary dyskinesia. Biol Reprod 85: 690-701, 2011.

37. Ostrowski LE, Andrews K, Potdar P, Matsuura H, Jetten A and Nettesheim P: Cloning and characterization of KPL2, a novel gene induced during ciliogenesis of tracheal epithelial cells. Am J Respir Cell Mol Biol 20: 675-683, 1999.

38. Finn R, Evans CC and Lee L: Strain-dependent brain defects in mouse models of primary ciliary dyskinesia with mutations in Pcdp1 and Spef2. Neuroscience 277: 552-567, 2014.

39. Chang PW, Tsui SK, Liew C, Lee CC, Waye MM and Fung KP: Isolation, characterization and chromosomal mapping of a novel cDNA clone encoding human selenium binding protein. J Cell Biochem 64: 217-224, 1997.

40. Porat A, Sagiv Y and Elazar Z: A 56-kDa selenium-binding protein participates in intra-Golgi protein transport. J Biol Chem 275: 14457-14465, 2000.

41. Ansong E, Ying Q, Ekoue DN, Deaton R, Hall AR, Kajdacsy-Balla A, Yang W, Gann PH and Diamond AM: Evidence that selenium binding protein 1 is a tumor suppressor in prostate cancer. PLoS One 10: e0127295, 2015.

42. Jeong JY, Zhou JR, Gao C, Feldman L and Sytkowski AJ: Human selenium binding protein-1 (hSP56) is a negative regulator of HIF-1 $\alpha$ and suppresses the malignant characteristics of prostate cancer cells. BMB Rep 47: 411-416, 2014.

43. Jiang H, Huang Y, Xu H, Hu R and Li QF: Inhibition of hypoxia inducible factor- $1 \alpha$ ameliorates lung injury induced by trauma and hemorrhagic shock in rats. Acta Pharmacol Sin 33: 635-643, 2012. 